XLVIth Zakopane School of Physics, International Symposium Breaking Frontiers, Zakopane, Poland, May 16-21, 2011

\title{
Nanocomposite Polymer Scaffolds for Bone Tissue Regeneration
}

\author{
E. Stodolak-Zych ${ }^{a, *}$, A. FrączeK-Szczypta ${ }^{a}$, A. WiecheĆ ${ }^{b}$ And M. BeAżeWicz ${ }^{a}$ \\ ${ }^{a}$ Faculty of Material Science and Ceramic, Department of Biomaterials \\ AGH-University of Science and Technology, Kraków, Poland \\ ${ }^{b}$ The Henryk Niewodniczański Institute of Nuclear Physics, Polish Academy of Sciences, Kraków, Poland
}

\begin{abstract}
Nanocomposite polymer scaffolds for tissue engineering were prepared using leaching method. As a porogen there were used phosphate salts with different grain size $(100-400 \mu \mathrm{m})$. Nanocomposite materials based on polylactide (PL/DLA) containing $2 \mathrm{wt} \%$ of ceramic bioactive nanoadditives $\left(\mathrm{SiO}_{2}\right)$ were prepared. The nanoadditive was characterized by dynamic light scatering (DLS) (size) and the Brunauer-Emmett-Teller (specific surface area) methods. Morphology of the nanoparticles was observed using the transmission electron microscopy. The optimal concentration of the nanofiller in the polymer matrix was evaluated on the basis of in vitro tests of the nanocomposite foils contacted with osteoblast-like human cells of MG63 line. The morphology and porosity of the scaffold after leaching was evaluated using scanning electron microscopy and hydrostatic weighing. The bioactivity test made on the scaffolds demonstrated ability to nucleation of apatite structure on the material.
\end{abstract}

PACS: $82.35 . \mathrm{Np}$

\section{Introduction}

Perspective materials for production of new generation scaffolds for bone tissue regeneration are polymeric-based nanocomposites. This structure plays a role of an artificial extra-cellular matrix (ECM) which serves as temporary support where isolated cells are introduced to form a tissue. The scaffold should be biocompatible, biodegradable, promote cell attachment and should be mechanically stable [1-3]. High porosity and pore interconnectivity is essential to ensure sufficient nutrient diffusion through the scaffold, i.e., nutrients towards the cells and transport of oxygen and allow metabolic products to be removed [4]. Additionally, porosity appears to have a positive effect on cell attachment as well [5].

The ideal scaffold should possess mechanical properties adequate to support growing bone tissue, degrade upon bone tissue growth and have high porosity with interconnecting pores enabling ingrowth of osteoblasts cells [6]. Unfortunately, polymeric materials such as polyesters, polyhydroxyacids might not have sufficient mechanical strength, which can be improved by adding reinforcements resulting in composites or nanocomposites.

The new direction in tissue engineering is modification of a polymer matrix with nanoparticles which can influence on mechanical, electrical, physicochemical and biological properties much more suitable for human body. As bioactive compounds of nanocomposite materials can be used: silica $\left(\mathrm{SiO}_{2}\right)$, hydroxyapatite $(\mathrm{HA})$, tricalcium phosphate (TCP) or carbon nanotubes (CNT) [7]. Silica $\left(\mathrm{SiO}_{2}\right)$ plays a fundamental role in bioactive glasses because silanolan groups interact with calcium and phos-

* corresponding author; e-mail: stodolak@agh.edu.pl phate ions forming an amorphous calcium phosphate which also can be found in the natural bone [8]. HA is used as an inorganic biomaterial since it is the major mineral component of bones and teeth. It has excellent biocompatibility with bone tissue because of its osteoconductive capabilities [9]. The remarkable mechanical and electrical properties of CNTs and their appropriate biocompatibility make them an excellent candidate for production of bone scaffold. Bone cell functions are stimulated with electrical impulse and therefore conductive nanoadditives such as carbon nanotubes may play a role in promoting osteoblast growth and proliferation [10].

The aim of this study was preparation and testing of $\mathrm{PL} / \mathrm{DLA}$-based nanocomposite scaffolds containing $\mathrm{SiO}_{2}$ as a ceramic bioactive nanoadditive. Our preliminary studies showed that $2 \mathrm{wt} \%$ of the nanofiller improves mechanical properties such as the Young modulus and tensile strength [11]. It was shown that small amount of the nanofiller resulted in increasing proliferation of osteoblast-like cells contacted with PL/DLA [12, 13]. The studies proved that nano- $\mathrm{SiO}_{2}$ altered so far inert polymeric material to bioactive one. Observed nucleation of apatite structure on the nanocomposite surface was a proof of suitable body response for the material. The nanocomposite scaffolds were obtained by leaching of porogen (disodium hydrophosphate) which was added to $\mathrm{PL} / \mathrm{DLA} / \mathrm{SiO}_{2}$ suspension at various weight fractions, i.e. $20,30,40,50,60,70,80 \mathrm{wt} \%$. The porogen was dissolved in hot water until the immersion solution reached conductivity of distilled water i.e. $3.5 \mu \mathrm{S} / \mathrm{cm}$. Morphology of the scaffolds, and shape and size of pores was observed using the scanning electron microscope (SEM). Porosity of the scaffolds was measured by hydrostatic weighing. Bioactivity of the $\mathrm{PL} / \mathrm{DLA} / \mathrm{SiO}_{2}$ scaffolds was determined by their incubation in simulated body 
fluid (SBF) and verified using the scanning electron microscopy (SEM/EDS).

\section{Materials and methods}

The nanocomposite component used to modify poly(L/DL)-lactide (PL/DLA) precursor was nanometric silica $\left(\mathrm{SiO}_{2}\right)$ provided by Aldrich (Germany). Its size was determined by DLS method (Zetasizer Nano-ZS, Malvern Instr.) and its specific surface area was measured by the Brunauer-Emmett-Teller (BET) method (Nova 1200e, Quantachrome Inc.). Results of the characterization are shown in Table I. A L-lactide/DL-lactide copolymer with ratio M/M\%: 80:20 (Purasorb ${ }^{\circledR}$ PLDL 8038, Purac) with molecular weight $200 \mathrm{kDa}$ was used to obtain thin nanocomposite foils.

Characteristics of the nanoadditive.

TABLE I

\begin{tabular}{c|c|c|c}
\hline \hline & $\begin{array}{c}\text { Diameter } \\
\text { (DLS method) }\end{array}$ & $\begin{array}{c}\text { Diameter } \\
\text { (TEM observation) }\end{array}$ & $\begin{array}{c}\text { Specific surface area } \\
\text { (BET method) }\end{array}$ \\
\hline $\mathrm{SiO}_{2}$ (Aldrich) & $5-10 \mathrm{~nm}$ & $50-80 \mathrm{~nm}$ & $350 \mathrm{~m}^{2} / \mathrm{g}$
\end{tabular}

TABLE II

Porosity (\%) of the scaffolds produced from various concentrations of the porogen.

\begin{tabular}{c|c|c|c|c|c|c|c|c}
\hline \hline Amount of the porogen & $20 \%$ & $30 \%$ & $40 \%$ & $50 \%$ & $60 \%$ & $70 \%$ & $80 \%$ & $90 \%$ \\
\hline $\mathrm{PL} / \mathrm{DLA}$ scaffolds & 13 & 28 & 37 & 45 & 52 & 62 & 68 & 76 \\
$\mathrm{PL} / \mathrm{DLA} / \mathrm{SiO}_{2}$ scaffolds & 14 & 26 & 32 & 49 & 56 & 65 & 73 & 81
\end{tabular}

TABLE III

Chemical composition of simulated body fluid (SBF) and body plasma $(\mathrm{pH}=7.4)$.

\begin{tabular}{c|c|c|c|c|c|c|c|c}
\hline \hline \multirow{2}{*}{ Fluid } & \multicolumn{7}{c}{ Concentration $[\mathrm{mM}]$} \\
\cline { 2 - 9 } & $\mathrm{Na}^{+}$ & $\mathrm{K}^{+}$ & $\mathrm{Mg}^{2+}$ & $\mathrm{Ca}^{2+}$ & $\mathrm{Cl}^{-}$ & $\mathrm{HCO}_{3}^{-}$ & $\mathrm{HPO}_{4}^{2-}$ & $\mathrm{SO}_{4}^{2-}$ \\
\hline plasma & 142.0 & 5.0 & 1.5 & 2.5 & 103.0 & 27.0 & 1.0 & 0.5 \\
SBF & 142.0 & 5.0 & 1.5 & 2.5 & 148.8 & 4.2 & 1.0 & 0.5
\end{tabular}

Morphology of the silica nanoparticles was observed using transmission electron microscope (TEM, Joel JEM1011). The $\mathrm{SiO}_{2}$ powder consisted of round primary particles with sizes within the nanometric range i.e. 50$80 \mathrm{~nm}$ which formed bigger agglomerates (Fig. 1).

The nanoadditive was immersed in dichloromethane (DCM) solution and sonicated at room temperature using ultrasonic homogenizer, then PL/DLA was added to the $\mathrm{DCM} / \mathrm{SiO}_{2}$ solution and sonicated at room temperature using the same homogenizer, then the mixture was homogenized by mechanical stirring for $24 \mathrm{~h}$. Such prepared suspensions were mixed with different weight fraction of porogen (disodium hydrophosphate). Several nanocomposite samples of $\mathrm{PL} / \mathrm{DLA} / \mathrm{SiO}_{2}$ containing from 20 to $80 \mathrm{wt} \%$ of the porogen were prepared. Mixture of $\mathrm{PL} / \mathrm{DLA} / \mathrm{SiO}_{2} / \mathrm{Na}_{2} \mathrm{HPO}_{4}$ was poured into a beaker and left to evaporate the solvent at room temperature. Produced solid materials were immersed in hot water until the immersion solution reached conductivity of distilled water i.e. $3.5 \mu \mathrm{S} / \mathrm{cm}$. In such way seven kinds of samples basing on the polylactide solution were prepared. As reference samples pure polymer PL/DLA

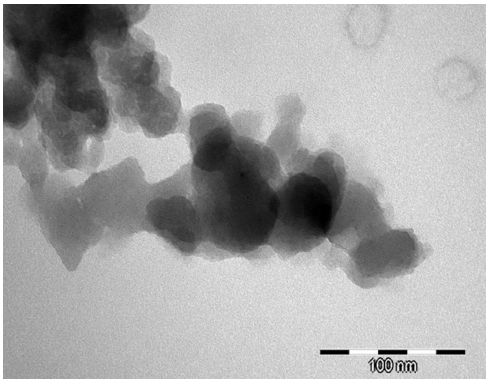

Fig. 1. Morphology of the silica nanoparticles. TEM microphotography.

scaffold was used. Biocompatibility of the materials was examined on the nanocomposite materials containing 1 or $2 \mathrm{wt} \%$ of the $\mathrm{SiO}_{2}$ contacted with human osteoblast-like cells of the MG-63 line (European Collection of Cell Cultures, Salisbury, UK). Their viability was measured after 1, 3 and 7 days of culture, and the cells were harvested by trypsin and counted in the Bürker chamber. 
A bioactivity test of the nanocomposite scaffolds consisted in incubation of the materials in SBF and microscopic inspection of their surface in order to determine their ability to nucleation of apatite structure.

\section{Results and discussion}

The applied method enabled to produce 3D samples of cylindrical shape and useful sizes i.e. diameter of $\approx 20 \mathrm{~mm}$ and height of $\approx 5 \mathrm{~mm}$, whose microstructure consisted of interconnected pores of different shape and size (Fig. 2.).

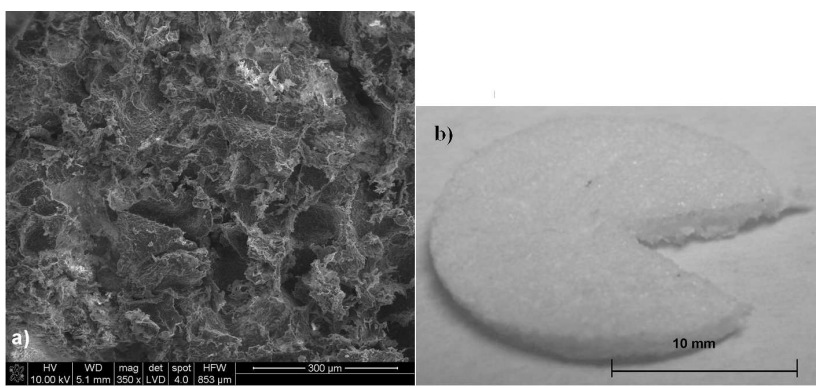

Fig. 2. Microstructure of PL/DLA scaffold (a), macroscopic view of the scaffold (b).

Observation of their microstructure confirmed that two populations of pores i.e., bigger ones whose sizes were about $350-500 \mu \mathrm{m}(35 \%)$ and smaller than $300 \mu \mathrm{m}(60 \%)$ were present. The presence of the silica in the polymer matrix did not influence neither shape and size of the pores nor the total porosity of the scaffolds. The silica nanoparticles changed only chemical composition of the scaffolds. Results shown in SEM/EDS microphotographs indicated the presence of silicon inside the nanocomposite scaffolds (Fig. 3).

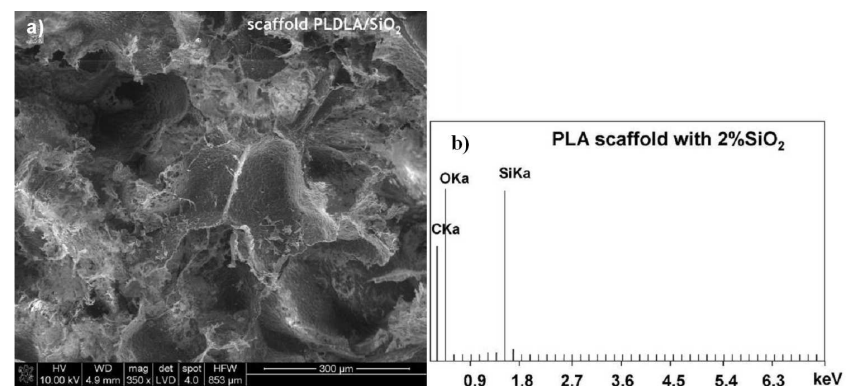

Fig. 3. Microstructure of the PLDLA $/ 2 \%-\mathrm{SiO}_{2}$ scaffold with $49 \%$ porosity ( $50 \%$ porogen) and its EDS analysis.

Porosity of the scaffolds was measured by hydrostatic weighing. It was shown that the scaffolds were characterized by open porosity which was directly proportional to the amount of the porogen used to produce the scaffolds (Table II). The $\mathrm{SiO}_{2}$ nanoparticles did not influence number of pores but they shortened time of leaching of the porogen.

Bone defect regeneration is supported by suitable architecture of a scaffold (pores of about 200-400 $\mu \mathrm{m}$ size) and favorable physicochemical properties of the material such as proper wettability and surface free energy $[13,14]$. It seems that $3 \mathrm{D}$ porous structure obtained by the phosphate leaching stimulated adhesion and proliferation of the osteoblast cells. Preliminary studies carried on flat $\mathrm{PL} / \mathrm{DLA} / 2 \% \mathrm{SiO}_{2}$ foil showed that its surface wettability was about $65^{\circ}$ and its surface free energy was $18 \mathrm{~mJ} / \mathrm{m}^{2}$ $[12,13]$.

Design of well-functioning "constructions" for tissue engineering requires to provide suitable conditions for cells attachment, proliferation and organization, as well as to assure nutrition of the cells and removal of products of their metabolism [14]. They should also be characterized by adequate mechanical properties, which are generally difficult to obtain in the case of porous materials.

Our preliminary investigations showed that the best mechanical properties i.e. Young's modulus and tensile strength of the porous polymer ceramic nanomaterials were achieved when the amount of nanosilica was $1-2 \mathrm{wt} \%[12,13]$. Additionally, the best dispersion of the nanofiller in the polymer matrix was observed for $2 \mathrm{wt} \%$ addition. Moreover, higher amounts of the nanofiller e.g. $5 \mathrm{wt} \%$ led to its agglomeration which in turn decreased mechanical strength of the material [13].

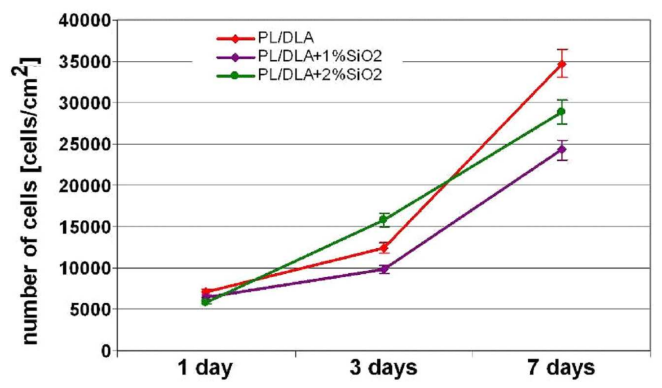

Fig. 4. Viability of the osteoblast-like cells contacted with $\mathrm{PL} / \mathrm{DLA}$ and $\mathrm{PL} / \mathrm{DLA} / \mathrm{SiO}_{2}$ foils.

The present investigations were only dedicated to testing of biological properties of the nanocomposite materials. Results of biological studies showed that after 7 days of incubation viability of the osteoblast-like cells contacted with the materials was higher for the pure polymer than for the nanocomposite materials (Fig. 4). On the other hand, after 3 days of incubation higher number of the cells was present on the $\mathrm{PL} / \mathrm{DLA} / 2 \% \mathrm{SiO}_{2}$ nanocomposite surface. The conventional in vitro test with the continuous line usually lasts 7 days and its aim is to observe stimulation of cells proliferation by a given material. Number of cells is determined after 1, 3 and 7 days of the test, respectively [14-16]. Probably the osteoblast cells contacted with the nanocomposite surface formed a multilayer structure, which made difficult flow of nutrients towards cells located on lower layers which eventu- 
ally resulted in their detachment. The best biocompatibility was observed in the case of the nanocomposites containing $2 \mathrm{wt} \%$ of the silica, and for that reason they were chosen for the further studies.

Nanocomposite scaffolds containing bioactive nanoparticles may be osteoconductive [17-19]. Treatment of the nanocomposite samples in SBF induced some changes on surface of the materials containing $\mathrm{SiO}_{2}$ nanoparticles [20, 21]. Composition of SBF immersing solution and body plasma is presented in Table III.

Apatite nucleation was observed after 6 days of incubation of the nanocomposite samples in SBF solution only in the case of scaffolds with $\approx 50 \%$ porosity. Other PL/ DLA $/ 2 \% \mathrm{SiO}_{2}$ samples did not indicate apatite structure after so short incubation time, and required prolonged immersion in SBF. Crystalline forms with morphology typical for apatite were observed inside pores of the scaffold with $\approx 50 \%$ porosity. EDS analysis indicated higher concentrations of such elements as phosphorus and calcium which confirmed the presence of apatite on the pores surface (Fig. 5). Such properties are required for better chemical fixation between a scaffold and bone tissue [22-24].

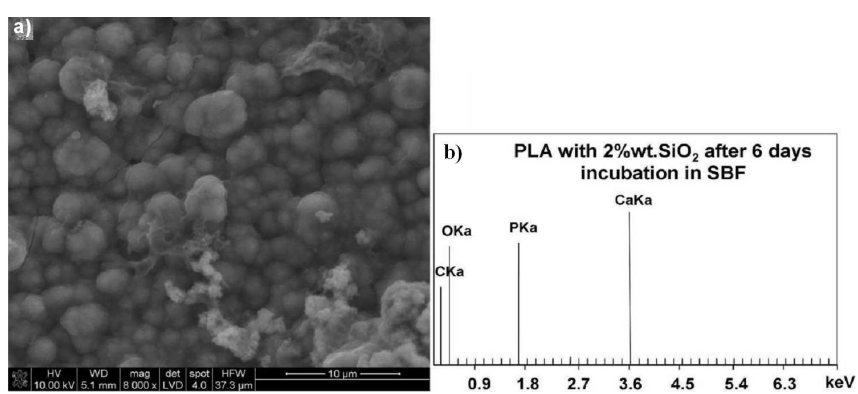

Fig. 5. Microstructure and EDS analysis of PL/DLA/ $2 \% \mathrm{SiO}_{2}$ scaffold with $50 \%$ of porosity after 6 days incubation in SBF solution.

\section{Summary}

The leaching method used to form porous 3D materials was successful to control amount of open porosity of the scaffolds. Using of phosphate salt as a porogen allowed its fast removing and creation of interconnected pores and channels. Morphology of the pores i.e. shape and size were suitable for promoting bone tissue for faster regeneration process. Dispersion of the nanofiller $\left(\mathrm{SiO}_{2}\right)$ in a resorbable matrix of poly $(\mathrm{L} / \mathrm{DL})$-lactide is a promising route for preparation of bioactive nanocomposite scaffold. The silica nanoparticles present in the nanocomposite foils acted as apatite nucleation centers and accelerated its crystallization. Chemically active bonds created on the scaffold surface i.e. $\mathrm{Si}-\mathrm{O}$ on PLDLA $/ 2 \% \mathrm{SiO}_{2}$ constituted biomimetic structure of an apatite. The produced materials seem to be promising in regenerative medicine applications.

\section{Acknowledgments}

This work was financially supported by the Polish Ministry of Science and Higher Education, project no. N N507 463537.

\section{References}

[1] C. Liu, Z. Xia, J.T. Czernuszka, Chem. Eng. Res. Des. 85, 1051 (2007).

[2] D.W. Hutmacher, J. Biomater. Sci., Polym. Ed. 12, 107 (2001).

[3] Y. Ito, J. Zheng, Y. Imanishi, Biomaterials 18, 197 (1997).

[4] R.Y. Kannan, H.J. Salacinski, K. Sales, P. Butler, A.M. Seifalian, Biomaterials 26, 1857 (2005).

[5] S.J. Hollister, Nat. Mater. 4, 518 (2005).

[6] B. Sitharaman, X. Shi, X.F. Walboomers, H. Liao, V. Cuijpers, L.J. Wilson, A.G. Mikos, J.A. Jansen, Bone 43, 362 (2008).

[7] H.M. Kim, Curr. Opin. Solid State Mater. Sci. 7, 289 (2003).

[8] A. Vallés-Lluch, G. Gallego Ferrer, M. Monleón Pradas, Eur. Polym. J. 46, 910 (2010).

[9] P. Zhang, Z. Hong, T. Yu, X. Chen, X. Jing, Biomaterials 30, 58 (2009).

[10] K. Sahithi, M. Swetha, K. Ramasamy, N. Srinivasan, N. Selvamurugan, Int. J. Biol. Macromol. 46, 281 (2010).

[11] A. Frączek-Szczypta, E. Stodolak, A. Wiecheć, M. Błażewicz, Eng. Biomat. 13, 1 (2010).

[12] E. Stodolak-Zych, A. Frączek-Szczypta, M. Błażewicz, Modern polymeric materials for environmental applications 4, 169 (2010).

[13] E. Stodolak, A. Frączek-Szczypta, M. Błażewicz, Kompozyty 10, 322 (2010) (in Polish).

[14] C.J. Kirkpatrick, K. Peters, M. Hermanns, F. Bittinger, V. Krump-Konvalinkova, S. Fuchs, R. Unger, ITB-MRBM 26, 192 (2005).

[15] European Standard: EN ISO 109935: 1999 (1999).

[16] European Standard: EN ISO 109931: 2004 (2004).

[17] V. Karageorgiou, D. Kaplan, Biomaterials 26, 5474 (2005).

[18] T. Takezawa, Biomaterials 24, 2267 (2003).

[19] T. Takezawa, Biomaterials 24, 2267 (2003).

[20] G.E. Poinern, R.K. Brundavanam, N. Mondinos, Z.T. Jiang, Ultrason Sonochem. 16, 469 (2009).

[21] X. Liu, C. Ding, P.K. Chu, Biomaterials 25, 1755 (2004).

[22] S. Yu, K.P. Hariram, R. Kumar, P. Cheang, K.K. Aik, Biomaterials 26, 2343 (2005).

[23] T. Kokubo, H. Takadam, Biomaterials 27, 2907 (2006).

[24] P.U. Rokkanen, O. Böstman, E. Hirvensalo, E.A. Mäkelä, E.K. Partio, H. Pätiälä, Biomaterials 21, 2607 (2000). 